\begin{tabular}{|c|c|c|c|c|c|}
\hline $\begin{array}{l}\text { These questions concern your feelings over the past } 4 \text { weeks about } \\
\text { the skin condition that has bothered you the most. Check the } \\
\text { answer that comes closest to the way you have been feeling. }\end{array}$ & NEVER & RARELY & SOMETIMES & OFTEN & $\begin{array}{l}\text { ALL THE } \\
\text { TIME }\end{array}$ \\
\hline 1. My skin hurts & $\square_{1}$ & $\square_{2}$ & $\square_{3}$ & $\square_{4}$ & $\square_{5}$ \\
\hline 2. My skin condition affects how well I sleep & $\square_{1}$ & $\square_{2}$ & $\square_{3}$ & $\square_{4}$ & $\square_{5}$ \\
\hline 3. I worry that my skin condition may be serious & $\square_{1}$ & $\square_{2}$ & $\square_{3}$ & $\square_{4}$ & $\square_{5}$ \\
\hline 4. My skin condition makes it hard to work or do hobbies & $\square_{1}$ & $\square_{2}$ & $\square_{3}$ & $\square_{4}$ & $\square_{5}$ \\
\hline 5. My skin condition affects my social life & $\square_{1}$ & $\square_{2}$ & $\square_{3}$ & $\square_{4}$ & $\square_{5}$ \\
\hline 6. My skin condition makes me feel depressed & $\square_{1}$ & $\square_{2}$ & $\square_{3}$ & $\square_{4}$ & $\square_{5}$ \\
\hline 7. My skin condition burns or stings & $\square_{1}$ & $\square_{2}$ & $\square_{3}$ & $\square_{4}$ & $\square_{5}$ \\
\hline 8. I tend to stay at home because of my skin condition & $\square_{1}$ & $\square_{2}$ & $\square_{3}$ & $\square_{4}$ & $\square_{5}$ \\
\hline 9. I worry about getting scars from my skin condition & $\square_{1}$ & $\square_{2}$ & $\square_{3}$ & $\square_{4}$ & $\square_{5}$ \\
\hline 10. My skin itches & $\square_{1}$ & $\square_{2}$ & $\square_{3}$ & $\square_{4}$ & $\square$ 唯 \\
\hline 11. My skin condition affects how close I can be with those I love & $\square_{1}$ & $\square_{2}$ & $\square_{3}$ & $\square_{4}$ & $\square_{5}$ \\
\hline 12. I am ashamed of my skin condition & $\square_{1}$ & $\square_{2}$ & $\square_{3}$ & $\square_{4}$ & $\square_{5}$ \\
\hline 13. I worry that my skin condition may get worse & $\square_{1}$ & $\square_{2}$ & $\square_{3}$ & $\square_{4}$ & $\square_{5}$ \\
\hline 14. I tend to do things by myself because of my skin condition & $\square_{1}$ & $\square_{2}$ & $\square_{3}$ & $\square_{4}$ & $\square_{5}$ \\
\hline 15. I am angry about my skin condition & $\square_{1}$ & $\square_{2}$ & $\square_{3}$ & $\square_{4}$ & $\square_{5}$ \\
\hline 16. Water bothers my skin condition (bathing, washing hands) & $\square_{1}$ & $\square_{2}$ & $\square_{3}$ & $\square_{4}$ & $\square_{5}$ \\
\hline 17. My skin condition makes showing affection difficult & $\square_{1}$ & $\square_{2}$ & $\square_{3}$ & $\square_{4}$ & $\square_{5}$ \\
\hline 18. I worry about side-effects from skin medications / treatments & $\square_{1}$ & $\square_{2}$ & $\square_{3}$ & $\square_{4}$ & $\square_{5}$ \\
\hline 19. My skin is irritated & $\square_{1}$ & $\square_{2}$ & $\square_{3}$ & $\square_{4}$ & $\square_{5}$ \\
\hline 20. My skin condition affects my interactions with others & $\square_{1}$ & $\square_{2}$ & $\square_{3}$ & $\square_{4}$ & $\square_{5}$ \\
\hline 21. I am embarrassed by my skin condition & $\square_{1}$ & $\square_{2}$ & $\square_{3}$ & $\square_{4}$ & $\square_{5}$ \\
\hline 22. My skin condition is a problem for the people I love & $\square_{1}$ & $\square_{2}$ & $\square_{3}$ & $\square_{4}$ & $\square 5$ \\
\hline 23. I am frustrated by my skin condition & $\mathbf{\square}_{1}$ & $\square_{2}$ & $\square_{3}$ & $\square_{4}$ & $\square_{5}$ \\
\hline 24. My skin is sensitive & $\square_{1}$ & $\square_{2}$ & $\square_{3}$ & $\square_{4}$ & $\square$ 唯 \\
\hline 25. My skin condition affects my desire to be with people & $\square_{1}$ & $\square_{2}$ & $\square_{3}$ & $\square_{4}$ & $\square_{5}$ \\
\hline 26. I am humiliated by my skin condition & $\square_{1}$ & $\square_{2}$ & $\square_{3}$ & $\square_{4}$ & $\square_{5}$ \\
\hline 27. My skin condition bleeds & $\square_{1}$ & $\square_{2}$ & $\square_{3}$ & $\square_{4}$ & $\square_{5}$ \\
\hline 28. I am annoyed by my skin condition & $\square_{1}$ & $\square_{2}$ & $\square_{3}$ & $\square_{4}$ & $\square 5$ \\
\hline 29. My skin condition interferes with my sex life & $\square_{1}$ & $\square_{2}$ & $\square_{3}$ & $\square_{4}$ & $\square_{5}$ \\
\hline 30. My skin condition makes me tired & $\square_{1}$ & $\square_{2}$ & $\square_{3}$ & $\square_{4}$ & $\square_{5}$ \\
\hline 31. I worry about going outside because the sun might flare my disease & $\square_{1}$ & $\square_{2}$ & $\square_{3}$ & $\square_{4}$ & $\square_{5}$ \\
\hline 32. I am worried about my hair loss & $\square_{1}$ & $\square_{2}$ & $\square_{3}$ & $\square_{4}$ & $\square_{5}$ \\
\hline 33. My skin disease prevents me from doing outdoor activities & $\square_{1}$ & $\square_{2}$ & $\square_{3}$ & $\square_{4}$ & $\square_{5}$ \\
\hline $\begin{array}{l}\text { 34. When talking to someone, I worry about what they may be thinking of } \\
\text { me }\end{array}$ & $\square_{1}$ & $\square_{2}$ & $\square_{3}$ & $\square_{4}$ & $\square_{5}$ \\
\hline 35. My skin condition influences the clothes I wear & $\square_{1}$ & $\square_{2}$ & $\square_{3}$ & $\square_{4}$ & $\square_{5}$ \\
\hline $\begin{array}{l}\text { 36. My skin condition affects my grooming practices (e.g., haircut, use of } \\
\text { cosmetics) }\end{array}$ & $\square_{1}$ & $\square_{2}$ & $\square_{3}$ & $\square_{4}$ & $\square_{5}$ \\
\hline $\begin{array}{l}\text { 37. My skin condition affects my sun protection habits during recreation } \\
\text { (e.g., limiting exposure time during sun peak hours, seeking shade, }\end{array}$ & $\square_{1}$ & $\square_{2}$ & $\square_{3}$ & $\square_{4}$ & $\square_{5}$ \\
\hline
\end{tabular}

wearing a hat, long sleeves or pants)

Abstract 253 Figure 1 The CLE-specific quality of life measure CLEQoL

\section{IDENTIFICATION OF DAMAGE CLUSTERS IN SYSTEMIC LUPUS ERYTHEMATOSUS}

${ }^{1} \mathrm{Ga}$ Young Ahn, ${ }^{2}$ Jiyoung Lee, ${ }^{2}$ Soyoung Won, ${ }^{3} \mathrm{E}$ unji Ha, ${ }^{1}$ Hyoungyoung Kim, ${ }^{1} \mathrm{Ji}$ Soong Kim, 'Juyeon Kang, 'Bora Nam, 'So-Young Bang, ${ }^{4}$ Seung Cheol Shim, 'HyeSoon Lee, ${ }^{5}$ Kwangwoo Kim, ${ }^{1}$ Sang-Cheol Bae*. ${ }^{1}$ Department of Rheumatology, Hanyang University Hospital for Rheumatic Diseases; ${ }^{2}$ Clinical Research Center for Rheumatioid Arthritis; ${ }^{3}$ Department of Biology, Kyung Hee University; ${ }^{4}$ Division of Rheumatology, Department of Internal medicine, Chungnam National University; ${ }^{5}$ Department of Biology, Kyung Hee University, Republic of Korea

10.1136/lupus-2019-Ism.254

Background Damage in SLE is an irreversible change of organ system results from SLE involvement or adverse effects of medications. Recently, the awareness and evidence of subphenotypes in SLE has been increased. In this study, thus we are to identify damage clusters and compare organ damage involvement, demographic and clinical manifestations, mortality and weighted genetic risk score (GRS) between clusters.

Methods The study was conducted from Hanyang Bae lupus Cohort. Patients whose disease duration is less than 5 years were excluded to minimize potential confounding effects of disease duration. Patients were grouped into 3 clusters based on SLICC Damage Index (SDI) at last follow-up visit using Kmean cluster analysis. Comparison of characteristics between clusters were performed using ANOVA and Chi-square test. Results A total number of 1130 patients were analyzed. Both the last follow-up visit, musculoskeletal damage was the most frequent damage domain followed by ocular, renal and 
Abstract 254 Table 1 Comparison of disease activity, damage score and mortality between damage clusters

\begin{tabular}{|c|c|c|c|c|}
\hline Variables & Cluster $1(n=824)$ & Cluster $2(n=195)$ & Cluster $3(n=111)$ & $P$ value \\
\hline Age at SLE diagnosis & $27.87 \pm 10.60$ & $27.21 \pm 11.31$ & $25.56 \pm 10.36$ & 0.399 \\
\hline Female sex & $774(93.9)^{\mathrm{a}}$ & $169(86.7)^{c}$ & $102(91.9)$ & 0.002 \\
\hline Disease duration at last follow up, years & $12.07 \pm 5.42^{\mathrm{ab}}$ & $14.96 \pm 6.05^{c}$ & $14.06 \pm 5.84^{c}$ & $<0.001$ \\
\hline Weighted GRS & $1.56 \pm 1.09$ & $1.78 \pm 1.00$ & $1.43 \pm 1.12$ & $0.036^{5}$ \\
\hline Adjusted Mean SLEDAI & $3.96 \pm 2.21$ & $5.40 \pm 2.94$ & $4.20 \pm 2.94$ & $<0.001$ \\
\hline Mortality & $20(2.4)$ & $11(5.6)$ & $16(14.4)$ & $<0.001$ \\
\hline \multicolumn{5}{|l|}{ Damage involvement (at last follow-up) } \\
\hline Ocular & 0 & $113(58.0)$ & $16(14.4)$ & $<0.001$ \\
\hline Neuropsychiatric & 0 & $4(2.1)$ & $111(100.0)$ & $<0.001$ \\
\hline Renal & 0 & $108(55.4)$ & $11(9.9)$ & $<0.001$ \\
\hline Pulmonary & $60(7.3)$ & $20(10.3)$ & $19(17.1)$ & 0.002 \\
\hline Cardiovascular & $26(3.2)$ & $13(6.7)$ & $3(2.7)$ & 0.055 \\
\hline Peripheral vascular & $27(3.3)$ & $8(4.1)$ & $5(4.5)$ & 0.722 \\
\hline Gastrointestinal & $8(1.0)$ & $3(1.5)$ & $3(2.7)$ & 0.024 \\
\hline Musculoskeletal & $132(16.0)$ & $57(29.2)$ & $39(35.1)$ & $<0.001$ \\
\hline Skin & $31(3.8)$ & $10(5.1)$ & $7(6.3)$ & 0.367 \\
\hline Premature gonadal failure & 0 & $5(2.6)$ & $4(3.6)$ & $<0.001$ \\
\hline Diabetes Mellitus & $22(2.7)$ & $16(8.2)$ & $6(5.4)$ & 0.001 \\
\hline Malignancy & $47(5.7)$ & $7(3.6)$ & $3(2.7)$ & 0.237 \\
\hline
\end{tabular}

neuropsychiatric damage. Three separate damage clusters were identified. Cluster 1 included 824 (72.9\%) of patients. None of patients in cluster 1 was accompanied by ocular, neuropsychiatric, renal damage and premature gonadal failure. Patients in cluster 1 had significantly less pulmonary damage than cluster 3, significantly less diabetes mellitus than cluster 2 , and significantly less musculoskeletal damage than two the other clusters. Cluster $2(\mathrm{n}=195,17.3 \%)$ was represented by prevalent ocular $(58.0 \%)$ and renal $(55.4 \%)$ damage. Patients in cluster 2 had significantly more ocular, renal damage than two the other clusters. All the patients of cluster $3 \quad(n=111$, 9.8\%) was accompanied by neuropsychiatric damage (100\%). Patients in cluster 3 had significantly more musculoskeletal (35.1\%) damage than two the other clusters. Age of SLE diagnosis and autoantibody positivity were similar among 3 clusters. Adjusted mean SLEDAI (AMS) was highest in cluster 2 (Mean \pm SD, 6.7 \pm 4.8 ), and mortality was highest in cluster 3 . Weighted GRS showed no significant difference between clusters.

Conclusions We classified patients by patterns of damage involvement (damage cluster) within a SLE cohort. Renal and neuropsychiatric damage were the two distinct domain of damage that classified patients into 3 clinically meaningful clusters. Patients in cluster 2 (prevalent renal and glucocorticoid associated damage) had the highest AMS. The highest mortality was recognized in cluster with prevalent neuropsychiatric damage. Therefore, we should be attentive to prevent renal and neuropsychiatric damage to improve the survival.

Funding Source(s): Comparison of demographic and clinical characteristics between damage clusters

\section{RITUXIMAB THERAPY IN LUPUS NEPHRITIS RESISTANT TO CONVENTIONAL THERAPY: A SINGLE CENTER EXPERIENCE (CASE SERIES)}

${ }^{1}$ Berna Yurttas, ${ }^{2}$ Bugra Egeli, ${ }^{3}$ Serdal Ugurlu*. ${ }^{1}$ Cerrahpasa Medical Faculty; ${ }^{2}$ Istanbul University-Cerrahpasa, Cerrahpasa Medical Faculty; ${ }^{3}$ Division of Rheumatology, Department of Internal Medicine, Cerrahpasa Medical Faculty, Istanbul University-Cerrahpasa

\subsection{6/lupus-2019-Ism.255}

Background Lupus nephritis(LN) can be a cause of morbidity and mortality. The treatment of lupus nephritis can be challenging in some patients who are resistant to conventional immunosuppressive treatment. There are case series showing the efficacy of rituximab on systemic lupus erythematosus (SLE) patients, but there are no randomized clinical trials. Therefore, we evaluated the efficacy and safety of rituximab treatment in $\mathrm{LN}$ patients in our clinic retrospectively.

Methods We evaluated LN patients who were followed and treated with at least one course of rituximab in our clinic between 2013-2018, retrospectively. We evaluated all of the patients before rituximab treatment and 3 months after the final rituximab course with 24 hour proteinuria. Remission was defined as proteinuria below $500 \mathrm{mg} /$ day. Also, we evaluated the reason behind the cessation of rituximab during the follow-up whether it is a side effect or lack of efficacy.

Results Thirty-two patients (19 F, 13 M) were treated with rituximab. All of the patients had active lupus nephritis at initiation. Median of disease duration was 4 years. Diagnosis was proven by renal biopsy, except two patients, which is shown in table 1 of histological characteristics. Patients received an average of $4.2 \pm 3.8$ courses. All patients were 